\section{New TonoPen XL: comparison with the Goldmann tonometer}

\section{Abstract}

Purpose To compare the intraocular pressure (IOP) values obtained using a Goldmann tonometer (Haag-Streit) with those obtained with the new Tonopen XL (Mentor), which has certain differences compared with first- and second-generation models.

Methods The IOPs of 104 patients were assessed by Goldmann tonometer and Tonopen XL tonometer. Goldmann measurements was done first in $\mathbf{1 4 5}$ eyes and Tonopen measurements were done first in $\mathbf{5 3}$ eyes. Four observers measured the IOP.

Observers A, B and C used the Goldmann tonometer first and then the Tonopen $X \mathrm{~L}$, while observer $D$ used the Tonopen $X L$ first and then the Goldmann tonometer. The results were analysed by descriptive analysis and, when the distribution of the data was normal, paired $t$-test and Pearson's $r$ coefficient were used to compare and correlate IOP

M. lester

A. Mermoud

F. Achache

S. Roy

Hôpital Ophtalmique Jules Gonin

Lausanne, Switzerland

\section{M. lester}

Department of Neurological and Visual Sciences Ophthalmology B University of Genoa and Ophthalmic Division of the G. Gaslini Institute Genoa, Italy

Michele lester, MD Department of Neurological and Visual Sciences

Ophthalmology B University of Genoa and Ophthalmic Division of the G. Gaslini Institute clo Viale Teano 71/1 16147 Genoa, Italy

Tel: + 390103731131 Fax: + 390103538494 e-mail: iester@csita.unige.it

Proprietary interest: None

Received: 8 February 2000 Accepted in revised form: 16 June 2000 measurements between Goldmann and

Tonopen measurements. When the

distribution of the data was non-normal, the Wilcoxon matched-pair test and Spearman coefficient were used. The agreement between Goldmann and Tonopen values was also calculated. ANOVA test was used to compare the difference obtained by 'Goldmann minus Tonopen' measurements among the three different observers.

Results A statistically significant difference $(p<0.0001)$ was found between the IOP readings obtained by Goldmann tonometer and the Tonopen $X \mathrm{~L}$ and a significant correlation was found between the Goldmann values and Tonopen XL values $(p<0.001)$. When the Goldmann IOP was more than $20 \mathrm{mmHg}$ the Tonopen XL measurements were lower than the Goldmann values. Also in this group this difference was statistically significant. No significant difference was found between Goldmann values and Tonopen values among the three observers, even though a significant difference was found between Goldmann values and Tonopen values for observer $B$. When the values obtained by first the Goldmann tonometer and then the Tonopen $\mathrm{XL}$ were compared with those obtained by first the
MICHELE IESTER, ANDRE MERMOUD, FARID ACHACHE, SYLVAIN ROY

Tonopen $\mathrm{XL}$ and then the Goldmann tonometer, no significant difference was found between the two groups.

Conclusion The new Tonopen XL provides similar results to the Goldmann tomometer if $62 \%$ of the cases and was slightly less accurati than the Goldmann tonometer for extreme values, just like the previous Tonopen. Nevertheless the precision is good enough fol the purpose of adequate screening.

Key words Glaucoma, Goldmann tonometer, Intraocular pressure, Tonometer, Tonopen XL

Glaucoma is an ocular disorder characterised b visual field defect and optic nerve head damagl mainly due to an elevated intraocular pressure (IOP) that is too high for that optic nerve head Probably other risk factors such as ocular blood flow, optic disc appearance and ganglion cell degeneration are involved in the pathogenesis but the only treatable parameter is still the IOP: Several authors have shown that IOP reduction can decrease the progression of the glaucomatous disease. ${ }^{1,2}$

Since Goldmann introduced the applanation tonometer, based on the equilibrium between the applanation force and the ocular tissue, this measurement has been applied in our clinic practice and established itself as the gold standard for clinical measurement of IOP. In the last 10 years, several generations of Tonopen have been launched. This device uses the same physical principle as the Goldmann tonometer; except that the area of applanation is smaller both for human and animal. Calibration studies and comparison studies using the Goldmann tonometer and a previous version of the Tonopen have been published elsewhere. ${ }^{3-8}$

The aim of this study was to compare IOP values obtained using the Goldmann tonometel (Haag-Streit, Switzerland) with those using a new Tonopen (Tonopen XL, Mentor, Santa Barbara, CA) which has certain differences compared with first- and second-generation models. Internally the new software is known as version 2.1, and provides greater reliability in the identification of transducer voltage signals and needs less time than the previous versions to stabilise the transducer. Externally, this version of the Tonopen XL differs only by the 
addition of an eyelet on the end of the handle. This eyelet is meant to be used to attach a cord, to be looped around the neck of the user, to preclude dropping the instrument. There is no functional difference from the older Tonopen, and therefore no model change was registered.

\section{Patients and methods}

One hundred and four patients were consecutively recruited for this study. All the patients were admitted to the Jules Gonin Hospital (Lausanne, Switzerland) for an examination at the glaucoma unit.

Four observers measured the intraocular pressure with the Goldmann applanation tonometer and Tonopen XL tonometer. Three of them (observers A, B and C) used the Goldmann tonometer first and then the Tonopen XL and measured IOP of the first consecutive and volunteer patients of the glaucoma unit within 3 weeks. One observer, who was randomly chosen among the four, measured IOP using first the Tonopen $X L$ and then the Goldmann tonometer. To avoid any measurement bias when observer D had to use the Goldmann tonometer the scale of the tonometer was positioned on $15 \mathrm{mmHg}$ and he checked the scale value just at the end of the measurement.

The Goldmann tonometer consists of a counterweight balance attached to a plastic biprism. When the tip end touches the cornea, the applanated area is divided into two half circles by the biprism. These semicircles are particularly easy to view under blue light illumination after fluorescein application in the inferior fornix. The examiner adjusts the force applied on the globe by the tonometer control knob, so that the inner margin of the biprism semicircles just touch. This value is recorded.

The Mentor Tonopen XL is a hand-held electronic tonometer which measures IOP. The body of the instrument is specially designed to fit comfortably in the user's hand. Its dimensions are $7 \frac{1}{4}$ inch $\times 1$ inch $\times \frac{7}{8}$ inch and its weight is $64 \mathrm{~g}$. The stainless steel probe on the Tonopen XL tonometer contains a solid-state strain gauge which converts IOP to an electrical signal. The probe tip must be covered by a Latex protective membrane (Mentor OcuFilm Tip Covers), which was changed for each patient. Utilising a sophisticated 'single chip' microprocessor and electronics housed in the body of the instrument, the waveform produced by each touch to the anaesthetised corneal surface is analysed and stored for a statistical comparison process. Each single valid IOP reading is obtained by two different measurements the instrument automatically performs. One measurement is recorded when it first touches the cornea, and the second at the release after indentation. The value obtained is displayed digitally on the liquid crystal display. When four valid readings are obtained, the mean IOP is shown on the display and the standard deviation of the value obtained is displayed as a single horizontal bar above one of the four corresponding SD values (statistical reliability) $(5 \%, 10 \%, 20 \%,>20 \%)$. The range of measurement of the Tonopen $\mathrm{XL}$ varies from 5 to $80 \mathrm{mmHg}$. In this study the Tonopen was calibrated before each session.

\section{Goldmann tonometer measurements}

All the patients were in a sitting position and a topical anaesthetic drop with fluorescein was instilled in both eyes. Each patient positioned his or her head on the chinrest of a Haag-Streit slit-lamp biomicroscope and a Goldmann applanation measurement was performed in both eyes. The right eye was always chosen first. Patients were asked not to move their eyes, not to blink, and had to breathe through their nose while looking at a target point on the slit-lamp, in order to keep the visual axis parallel to the probe. Two measurements were done for each eye, the mean being calculated and used for statistical analysis.

\section{Tonopen XL measurements}

Patients were instructed to look straight ahead at a fixation target located at $5 \mathrm{~m}$. To facilitate the hand-held tonometer movements, the hand of the user was placed on the patient's forehead for stability. After having pushed the button to initiate an IOP measurement and waited for the beep sound, the probe tip was gently positioned on the patient's cornea, right in the centre to indent it. The Tonopen transducer was perpendicular to the apex of the cornea. If the measurement was valid, the value appeared on the digital display. The users took four measurements, waiting $7 \mathrm{~s}$ between each. After four valid measurements, a final beep sounded and the averaged measurement appeared on the LED display with the single bar denoting statistical reliability. In this study only a statistical reliability of $5 \%$ was considered. When statistical reliability was less than $5 \%$ the results were ignored, and the measurement was repeated. This operation was conducted twice for each eye, the mean of the two measurements being used for statistical analysis.

To avoid any intra-instrument variability, the same Goldmann tonometer and Tonopen XL tonometer were always used.

\section{Study details}

The study was divided in five parts:

1. All the measurements of the four observers were considered together, the difference and their correlation between the two instruments being calculated.

2. The absolute value of the difference between Goldmann measures and Tonopen values was calculated in the group which had the Goldmann measurements performed first.

3. The entire group was divided into three subgroups, ${ }^{3}$ based on the Goldmann values, to evaluate the possible influence of IOP on the measurements: (a) when the Goldmann IOP was $\leqslant 6 \mathrm{mmHg}$, (b) when the Goldmann IOP ranged from 4 to $24 \mathrm{mmHg}$, (c) when the Goldmann IOP was $\geqslant 24 \mathrm{mmHg}$. 
Table 1. Comparison of Goldmann and Tonopen XL tonometers: part 1 Goldmann values $(n=198)$

Mean (SD)

$15.6(5.7)$

Median

14

Range

4-34

Tonopen values $(n=198)$

Mean (SD)

$15.3(5.2)$

Median

15

Range

$4-36.5$

Difference 'Goldmann-Tonopen'

Mean (SD) $\quad 0.2(3.2)$

Wilcoxon test ( $p$ value) $\quad p<0.001$

Correlation

Spearman $r \quad 0.85(p<0.001)$

Linear regression $r \quad 0.67(p<0.001)$

$n$, number of patients.

4. The measurements of each observer who did the Goldmann measurements first (observers A, B and C) were analysed.

5. The results of observer $D$ were compared with the results of one of the other three observers who was chosen at random.

\section{Statistical analysis}

The results were analysed by descriptive analysis, and when the distribution of the data was normal, Student's paired $t$-test and Pearson's $r$ coefficient were used to compare and correlate IOP measurements between Goldmann and Tonopen measurements. When the distribution of the data was non-normal, a Wilcoxon matched pair test and Spearman coefficient were used.
The agreement between Goldmann and Tonopen measurements was also calculated by the difference between appropriate pairs of values for each subject against the mean of the two measures by Altman-Bland's method. ${ }^{9,10}$

The difference between the two techniques was calculated and was considered as an absolute value to represent the magnitude of the difference and to measure the tendency of the difference.

ANOVA was used to compare the difference obtained by 'Goldmann measurements' minus 'Tonopen measurements' among the three different observers and an unpaired $t$-test was used to compare the difference of the results of observer $D$ and one of the three observers.

A $p$ value less than 0.05 was considered to be statistically significant.

\section{Results}

Of 104 patients, only 198 eyes were measured. Goldmann measurements were done first in 145 eyes, and Tonopen measurements were done first in 53 eyes.

\section{Part 1}

A significant $(p<0.001)$ difference was found between the IOP readings obtained by Goldmann tonometer and the Tonopen XL. The Goldmann values were slightly greater than the Tonopen XL ones (Table 1). Using an AltmanBland plot, the mean difference between Goldmann values and Tonopen $\mathrm{XL}$ values was $0.15 \pm 10.5 \mathrm{mmHg}$ (mean \pm standard deviation) and the limits of agreement (95\% confidence interval) were -20.85 and 21.15 (Fig. 1). Between the Goldmann value and Tonopen XL values a

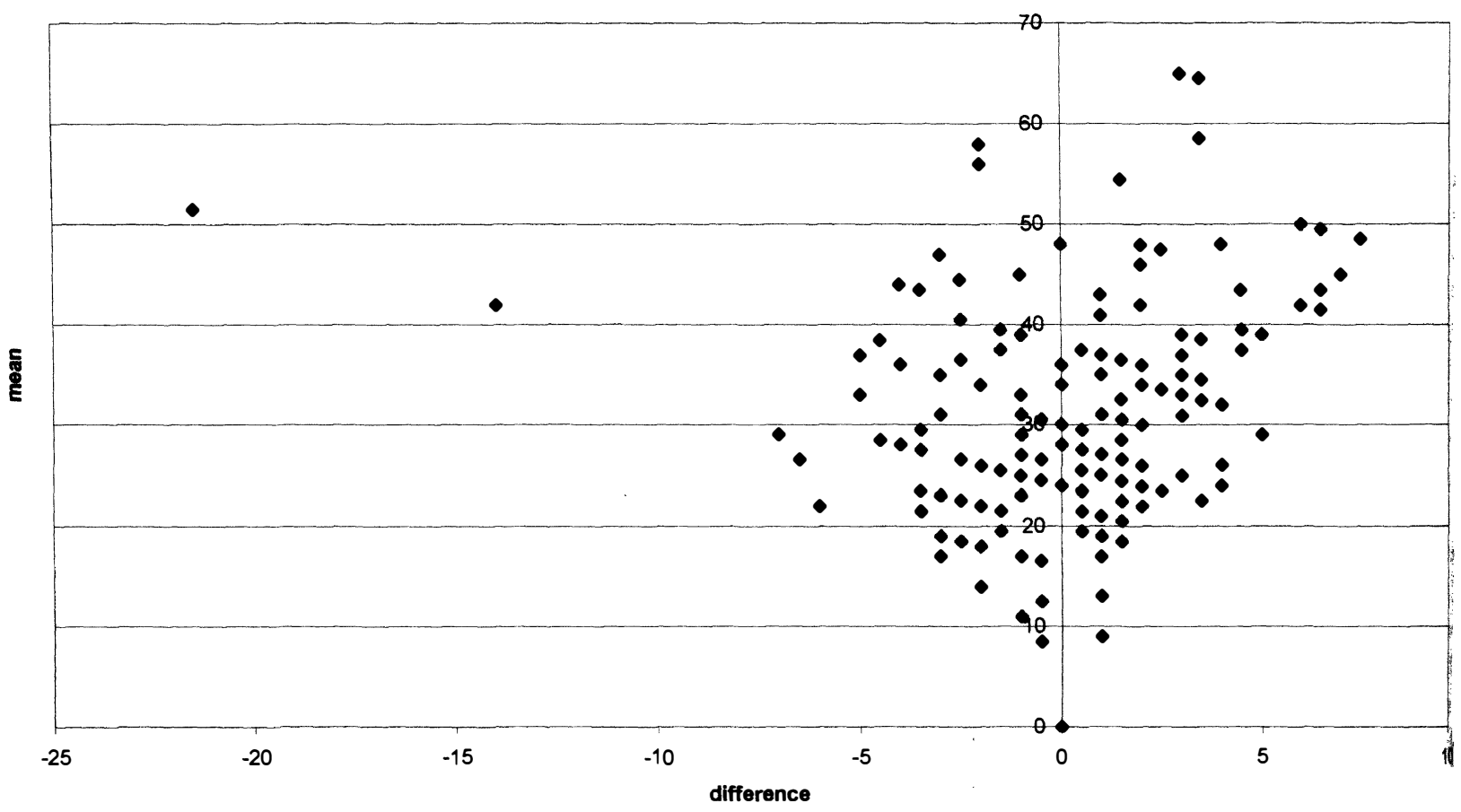

Fig. 2. Scattergram of the IOP obtained by the Tonopen XL tonometer ( $\mathrm{x}$-axis) and the IOP obtained by Goldmann tonometer (y-axis). 


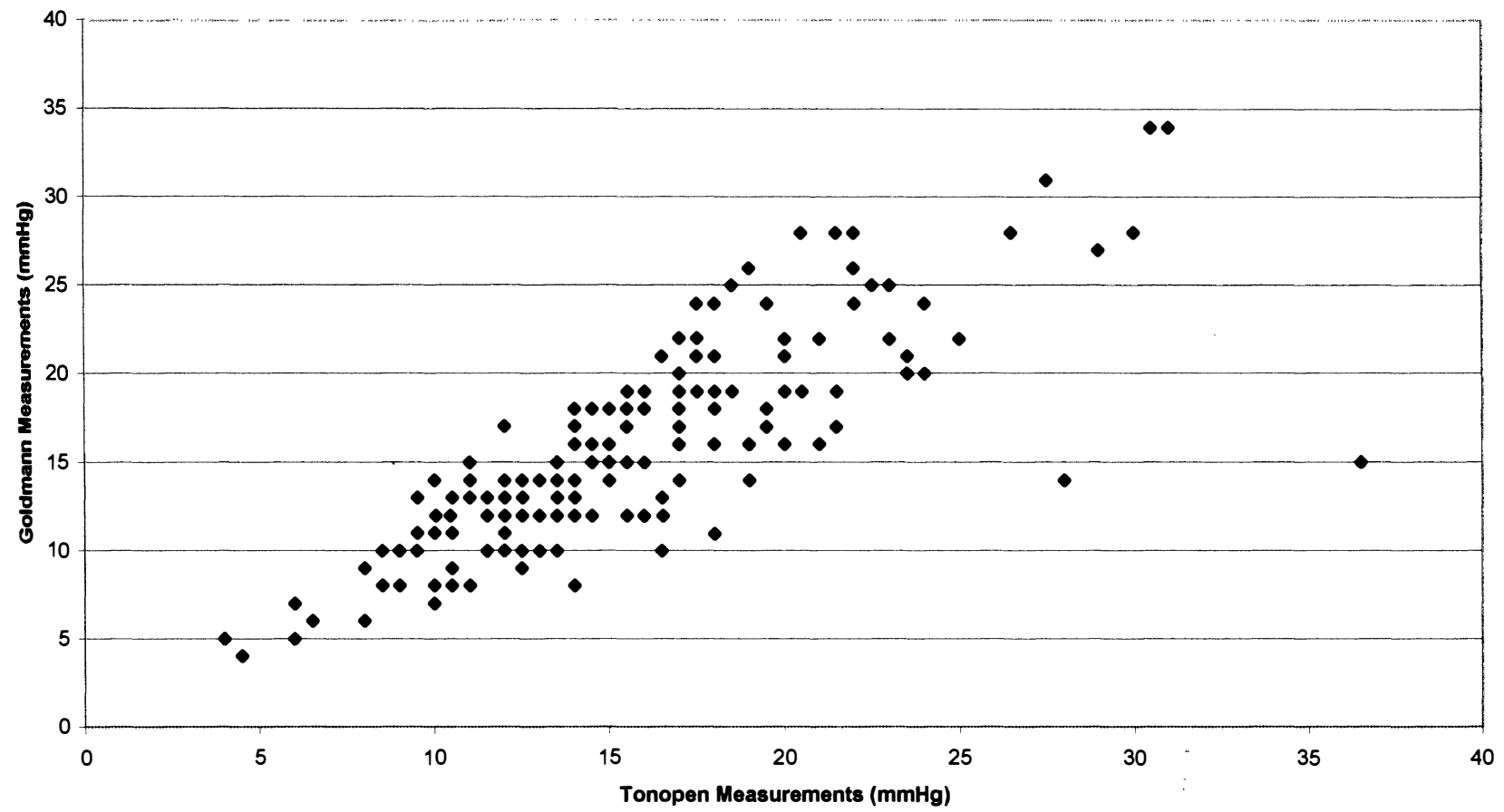

Fig. 1. Scattergram of the difference between the Tonopen and Goldmann pair of measures for each subject against the mean of the two measures. The mean difference was 0.15 and the $95 \%$ confidence interval was -20.85 to 21.15.

significant $(p<0.001)$ correlation was found by Pearson's $r$ coefficient $(r=0.85)$ and by linear regression analysis $\left(r^{2}=0.67, y=0.9 x+1.69\right)$ (Fig. 2).

\section{Part 2}

When the absolute value of the difference between Goldmann and Tonopen values was calculated, no difference was found in 11 measurements $(7.6 \%)$, in 90 measurements $(62 \%)$ the difference between the two instruments was $<2 \mathrm{mmHg}$, and in 112 patients $(77 \%)$ the difference was $<3 \mathrm{mmHg}$ (Fig. 3). The mean of the absolute value of the difference was $2.3+2.5 \mathrm{mmHg}$ and when a best cases analysis was created and two cases were not considered the mean was $2.1+1.7 \mathrm{mmHg}$. The two cases not included in the best cases analysis had normal Goldmann values (around $15 \mathrm{mmHg}$ ) and very high Tonopen values (27 and $36 \mathrm{mmHg}$ ).

\section{Part 3}

Then the group that had Goldmann measurements first followed by Tonopen measurements was also divided into three subgroups on the basis of the Goldmann IOP

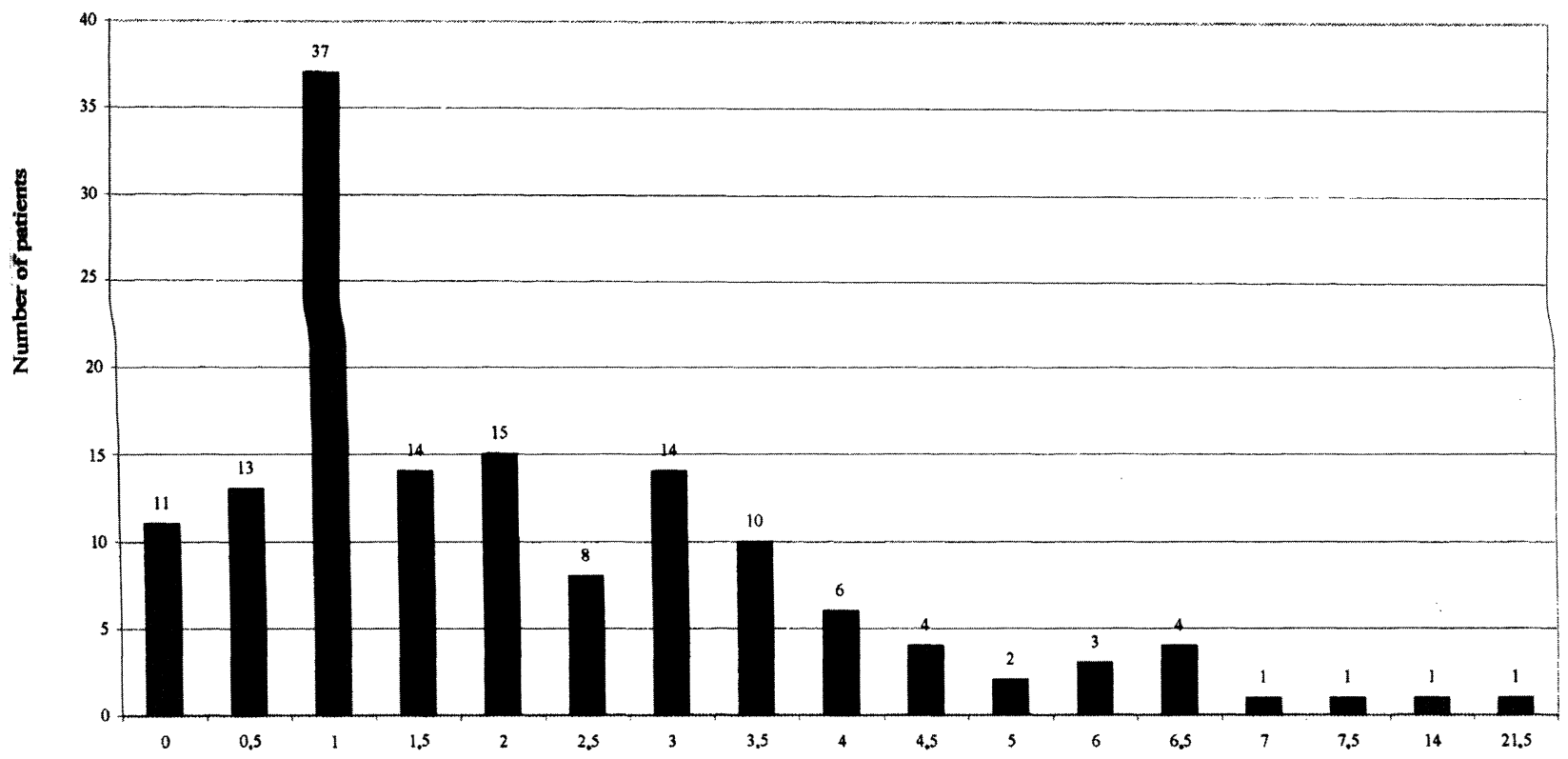

Difference in $\mathrm{mmHg}$

Fig. 3. Histogram of the absolute values of the difference between 'Goldmann value' minus 'Tonopen value' ( $\mathrm{x}$-axis) and the number of patients (y-axis). 
Table 2. Goldmann versus Tonopen XL measurements: part 3

\begin{tabular}{|c|c|c|c|c|}
\hline & All the considered eyes & $\mathrm{IOP} \leqslant 6 \mathrm{mmHg}$ & IOP 7-24 mmHg & $\mathrm{IOP} \geqslant 24 \mathrm{mmHg}$ \\
\hline No. of eyes & 145 & 7 & 126 & 12 \\
\hline \multicolumn{5}{|l|}{ Goldmann } \\
\hline Mean (SD) & $15.5(6)$ & $5(0.75)$ & $14.9(4.3)$ & $28.2(3.2)$ \\
\hline Median & 14 & 5 & 14 & 28 \\
\hline \multicolumn{5}{|l|}{ Tonopen } \\
\hline Mean (SD) & $15(5.2)$ & $5.6(1.5)$ & $14.8(4.3)$ & $23.3(4.1)$ \\
\hline Median & 14.5 & 5 & 14 & 22 \\
\hline \multicolumn{5}{|c|}{ Difference 'Goldmann-Tonopen' } \\
\hline \multirow[t]{2}{*}{ Mean (SD) } & $0.5(3.4)$ & $-0.57(1)$ & $0.1(3.3)$ & $4.8(2)$ \\
\hline & Wilcoxon test & $t$-test & Wilcoxon test & $t$-test \\
\hline$p$ value & NS & NS & NS & 0.004 \\
\hline \multirow[t]{2}{*}{ Correlation } & Spearman & Pearson & Spearman & Pearson \\
\hline & $0.82^{*}$ & $0.74^{*}$ & $0.70^{*}$ & $0.88^{*}$ \\
\hline
\end{tabular}

${ }^{*} p<0.0001$

value: 7 eyes were in the subgroup with IOP $\leqslant 6 \mathrm{mmHg}$, 126 eyes were in the subgroup with an IOP ranging from 7 to $24 \mathrm{mmHg}$ and 12 eyes were in the subgroup with IOP $\geqslant 24 \mathrm{mmHg}$ (Table 2). When the Goldmann IOP was more than $24 \mathrm{mmHg}$ the Tonopen $\mathrm{XL}$ values were lower than the Goldmann values, and in this group this difference was statistically significant. Below $24 \mathrm{mmHg}$ no significant difference was found between the two methods. Goldmann and Tonopen XL values were always significantly correlated (Table 2 ).

\section{Part 4}

When the measurements of each observer who measured IOP first by Goldmann tonometry and then by the Tonopen XL were analysed, observers A and B showed a greater Goldmann mean value and a smaller Tonopen mean value, while observer $C$ showed the opposite. No significant difference was found between Goldmann values and Tonopen values among the three observers, even though a significant difference was found between Goldmann values and Tonopen values for observer B. The measurements of each observer showed that Goldmann measurements were significantly correlated with the Tonopen XL measurements (Table 3).

Table 3. Goldmann versus Tonopen XL measurements: part 4

\begin{tabular}{lccc}
\hline & Observer A & Observer B & Observer C \\
\hline No. of eyes & 42 & 67 & 36 \\
Goldmann & & & \\
Mean (SD) & $16.9(6.2)$ & $15.8(6.3)$ & $13.2(4.1)$ \\
Median & 18 & 14 & 13 \\
Range & $4-31$ & $5-34$ & $4-21$ \\
Tonopen & & & \\
Mean (SD) & $16(7.1)$ & $14.8(5.1)$ & $13.5(3.8)$ \\
Median & 16.5 & 14 & 13.5 \\
Range & $4-36.5$ & $6-31$ & $4.5-24$ \\
Difference 'Goldmann-Tonopen & & & \\
Mean (SD) & $0.4(5.0)$ & $1.0(2.5)$ & $-0.3(2.3)$ \\
Paired $t$-test & $p=0.277$ & $p=0.002$ & $p=0.382$ \\
Pearson's $r$ & $0.67^{*}$ & $0.92^{*}$ & $0.84^{*}$ \\
\hline
\end{tabular}

${ }^{a}$ ANOVA, $p=0.157$, among the three observers. ${ }^{*} p<0.0001$.

\section{Part 5}

When the values obtained first by the Goldmann tonometer and then by the Tonopen XL by one of the three observers who was randomly chosen (observer $\mathrm{A}$ ) were compared with those values obtained first by Tonopen XL and then by Goldmann tonometry (observel D), no significant difference was found between the two observers' measurements (Table 4).

\section{Discussion}

Glaucoma is a major worldwide cause of blindness. Sinqe currently the only accepted treatment for glaucoma is reduction in the IOP, it is of importance to quantify accurately for the diagnosis and follow-up of patients. Normal IOP values have been statistically established bat other clinical parameters such as optic nerve head (ONH appearance and visual field have to be considered for the diagnosis of the disease. ${ }^{11}$ Some patients may present high IOP and no ONH damage and visual field defect and are diagnosed as having ocular hypertension, while others may present with a normal IOP associated with ONH damage and visual field defect and be diagnosed

Table 4. Comparison of Goldmann 'first' (observer A) versus Goldmann 'second' (observer D): part 5

\begin{tabular}{lcc}
\hline & Observer A & Observer D \\
\hline No. of eyes & 42 & 53 \\
Goldmann & & \\
Mean (SD) & $16.9(6.2)$ & $15.9(5.0)$ \\
Median & 18 & 15 \\
Range & $4-31$ & $7-28$ \\
Tonopen & & \\
Mean (SD) & $16(7.1)$ & $16.7(5.1)$ \\
Median & 16.5 & 16.5 \\
Range & $4-36.5$ & $6-30$ \\
Difference 'Goldmann-Tonopen & \\
Mean (SD) & $0.4(5.0)$ & $-0.8(2.5)$ \\
Paired $t$-test & 0.277 & 0.023 \\
Pearson's $r$ & $0.67^{*}$ & $0.88^{*}$ \\
\hline
\end{tabular}

${ }^{a}$ Unpaired $t$-test was not significant between observers $A$ and ${ }^{*} p<0.0001$. 
as having normal tension glaucoma. ${ }^{12}$ Nevertheless, the measurement of IOP is essential in the glaucoma clinic, reproducible and accurate measurements being required.

Many new tonometers have been introduced in recent years. They have all been compared with the Goldmann applanation tonometer, which has been considered for the last 40 years the gold standard. In 1987 Minckler et $a .^{3}$ found similar IOP readings using the Goldmann tonometer and the first generation of Tonopen (Tonopen-1). They reported that Tonopen-1 underestimated the IOP in eyes with a high IOP and overestimated the IOP in eyes with a low IOP. They showed that when the IOP was less than $5 \mathrm{mmHg}$ the overestimation was in the range of $1 \mathrm{mmHg}(p<0.2)$; for IOPs between 6 and $24 \mathrm{mmHg}$, the difference was $-1.7 \mathrm{mmHg}(p<0.0001)$; and when the IOP was more than $25 \mathrm{mmHg}$, the IOP was underestimated by $0.9 \mathrm{mmHg}$.

In a comparative study, Bordon et al. ${ }^{13}$ did not find any significant difference $(p>0.05)$ between IOP measurements obtained with the second generation of Tonopen (Tonopen-2) and the Perkins tonometer. Furthermore in the same study, Tonopen-2 measurements were significantly $(p<0.05)$ lower than those obtained with the Schiotz tonometer. ${ }^{13}$

Hessemer et al. ${ }^{14}$ compared the IOP value obtained with the Tonopen-1 and manometry in humans shortly after death and found that with the Tonopen a small underestimation was present when the IOP was above $17 \mathrm{mmHg}$, while a small overestimation was observed when IOP was below $17 \mathrm{mmHg}$. A similar finding applied to Tonopen-2 measurement compared with intracameral manometry in rabbits and rats. ${ }^{15,16}$

Eisenberg et al. ${ }^{7}$ found that Tonopen XL was the most accurate instrument in the laboratory setting, but when used intraoperatively it was the least accurate of the instruments they tested. However, they did not directly test it against the Goldmann tonometer. ${ }^{7}$ In particular the Tonopen XL underestimated IOP values in the age group they considered, which were heavily weighted with children $0-5$ years.

Our study showed a significant difference between the values obtained with the Goldmann and Tonopen XL tonometers and a good agreement between the two techniques; however, when the absolute value of the difference between Goldmann and Tonopen values was calculated, no difference was found in only $7.6 \%$ of the measurements, in $62 \%$ of the cases the difference between the two instruments was $<2 \mathrm{mmHg}$, and in $77 \%$ of the cases the difference was $<3 \mathrm{mmHg}$ (Fig. 3). In other words in $23 \%$ of the measurements the difference between the Goldmann tonometer and Tonopen was greater than $3 \mathrm{mmHg}$. Two cases showed a large disagreement between the two techniques, but when a best case analysis was considered and the two cases were deleted the results did not change much. However, no reason was found to explain these errors in the measurements.
When the values were analysed according to pressure categories, the Tonopen XL tonometer underestimated IOP when the Goldmann tonometer measurement exceeded $24 \mathrm{mmHg}$. Furthermore for IOP values exceeding $24 \mathrm{mmHg}$, the Tonopen tonometer values were less accurate (Table 2). However, for low IOP values, the Tonopen did not show any difference compared with the Goldmann tonometer measurements.

When the measurements of each single observer who measured IOP first by Goldmann tonometry and then by Tonopen XL were analysed, observers A and B showed a greater Goldmann mean value and a smaller Tonopen mean value, while observer $C$ showed the opposite (Table 3).

When the Goldmann tonometer was used first, the Tonopen XL IOP values were underestimated, while when Tonopen $\mathrm{XL}$ was used first an overestimation was noted (Table 4). These results could be due to the result of a mechanical dip in IOP after Goldmann applanation measurement. When the biprism of the Goldmann tonometer touches the human cornea it applanates the cornea over $3.06 \mathrm{~mm}^{2}$ causing a displacement of approximately $5 \mu \mathrm{l}$ of aqueous. This mechanical phenomenon could induce a small reduction in IOP that could be calculated as a decrease of $3 \%$ from the original value (before any measurements). This phenomenon could also occur after use of the Tonopen but in a smaller way because the surrounding diameter annulus is of $3.22 \mathrm{~mm}$. Both tonometers could create an iatrogenic decrease in IOP.

Other factors may also influence the IOP measurements. Using the Goldmann tonometer an increase or a decrease in the tear film may change (increase or decrease) the IOP measurement, the position of the biprism can change the thickness of the cornea with a significant over- and underestimation in values, the IOP value can be changed by the refractive and corneal surgery, by keratopathies, by the position of the body, by the season and by the refractive error (about $1 \mathrm{mmHg}$ per 3 dioptre). ${ }^{15-20}$

Misreadings may also be encountered using the Tonopen in situations such as: wrong tip cover tension, dirt on the transducer, frequent applanation measures. The transducer is calibrated to work with a tip cover which provides a very precise thickness and tension. In some patients allergic to Latex it has been reported that local and systemic reaction may induce a substantial reading change. ${ }^{21}$ Regarding the applanation technique, the Mentor Tonopen XL needs less time than the previous versions to stabilise the transducer, although with this new instrument the transducer still requires about $1 \mathrm{~s}$ between applanations to enhance the accuracy of Tonopen measurements. The tip must be always perpendicular to the cornea centre. The examiner's hand movement must be gentle and unhurried. Finally an overindentation of the corneal surface may result in erratic high readings.

In our study the Tonopen XL tonometer provides similar results ( $\leqslant 2 \mathrm{mmHg}$ ) to the Goldmann tonometer in $62 \%$ of the cases. This could be due to some limitation 
depending on how the tip touches the cornea. For clinical purposes the use of the $5 \%$ standard deviation is paramount. However, in clinics we believe it is still faster to use a Goldmann applanation measurement than a Tonopen XL one. With the Tonopen XL more time is needed to periodically clean the tip, to take measurement with $5 \%$ SD, and to calibrate the instrument. However, we took extraordinary care in our comparative study, which may have contributed to our impression. Certainly the Tonopen XL could be useful during out-of-office examinations or during surgery or for animal studies.

In conclusion, although Tonopen XL and Goldmann applanation measurements showed some difference we do find Tonopen $\mathrm{XL}$ to be accurate for screening or for out-of-office examinations.

The authors thank Donald H. Timm, Diagnostic Product Manager for Mentor Corporation, for information on the Tonopen XL.

\section{References}

1. Katz LJ, Spaeth GL, Cantor LB, Poryzees EM, Steinmann WC. Reversible optic disc cupping and visual field improvement in adults with glaucoma. Am J Ophthalmol 1989;107:485-92.

2. O'Brien C, Schwartz B, Takamoto T, Ching Wu D. Intraocular pressure and the rate of visual field loss in chronic openangle glaucoma. Am J Ophthalmol 1991;111:491-500.

3. Minckler DS, Baerveldt G, Heuer DK, Quillen-Thomas B, Walonker AF, Weiner J. Clinical evaluation of the Oculab Tonopen. Am J Ophthalmol 1987;104:168-72.

4. Kao SF, Lichter PR, Bergstrom TJ, Rowe S, Mush DC. Clinical comparison of the Oculab Tono-Pen to the Goldmann applanation tonometer. Ophthalmology 1987;94:1541-4.

5. Frenkel REP, Hong YJ, Shin DH. Comparison of the TonoPen to the Goldmann applanation tonometer. Arch Ophthalmol 1988;106:750-3.

6. Khan JA, Davis M, Graham CE, Trank J, Whitacre MM. Comparison of Oculab Tono-Pen readings obtained from various corneal and scleral locations. Arch Ophthalmol 1991;109:1444-6.

7. Eisenberg DL, Sherman BG, McKeown CA, Scuman JS. Tonometry in adults and children: a manometric evaluation of pneumatonometry, applanation, and Tonopen in vitro and in vivo. Ophthalmology 1998;105:1173-81.
8. Hessemer V, Rossler R, Jacobi KW. Tono-Pen, a new tonometer. Int Ophthalmol 1989;13:51-6.

9. Bland JM, Altman DG. Statistical methods for assessing agreement between two methods of clinical measurement. Lancet 1986;I:307-10.

10. Iester M, Mermoud A, Schnyder C. Frequency-doubling technique in subjects with ocular hypertension and glaucoma: correlation with Octopus perimeter indices. Ophthalmology 2000;107:288-94.

11. Nicolela MT, Drance SM. Various glaucomatous optic nervi appearances: clinical correlations. Ophthalmology 1996;1034:640-9.

12. Iester M, Broadway D, Mikelberg FS, Drance SM. A comparison of healthy, ocular hypertensive, and glaucomatous optic disc topographic parameters. J Glaucoma 1997;6:363-70.

13. Bordon AF, Katsumi O, Hirose T. Tonometry in pediatric patients: a comparative study among Tono-pen, Perkins and Schiotz tonometers. J Pediatr Ophthalmol Strabismus 1995;32:373-7.

14. Hessemer V, Rossler R, Jacobi KW. Comparison of intraocular pressure measurements with the Oculab TonoPen vs manometry in humans shortly after death. Am J Ophthalmol 1988;105:678-82.

15. Mermoud A, Baerveldt G, Minckler DS, Lee MB, Rao NA. Intraocular pressure in Lewis rats. Invest Ophthalmol Vis $\mathrm{S}$ 1994;35:2455-60.

16. Mermoud A, Baerveldt G, Minckler DS, Lee MB, Rao NA. Measurements of rabbit intraocular pressure with the Tond pen. Ophthalmologica 1995;209:275-7.

17. Azuara-Blanco A, Bhojani TK, Sarhan AR, Pillai CT, Dua HS Tono-pen determination of intraocular pressure in patients with band keratopathy or glue cornea. Br J Ophthalmol 1998;82:634-6.

18. Mok KH, Wong CSL, Lee VWH. Tono-pen tonometer and corneal thickness. Eye 1999;13:35-7.

19. Ménage MJ, Kaufman PL, Croft MA, Landay SP. Intraoculą measurement after penetrating keratoplasty: minified Goldmann applanation tonometer, pneumatonometer and Tono-pen versus manometry. Br J Ophthalmol 1994;78:671-4

20. Copt RP, Thomas R, Mermoud A. Corneal thickness in ocula hypertension, primary open-angle glaucoma, and normal tension glaucoma. Arch Ophthalmol 1999;117:14-6.

21. Bergwek KL, Kodsi SR. Latex allergy associated with the latex cover on the TonoPen. Am J Ophthalmol 1999;127:91. 